\title{
PRIMARY SPLENIC HYDATID CYST- A CASE REPORT
}

\author{
Saleem Tahir ${ }^{1}$, Shahriq Ahmad², Shadab Asif ${ }^{3}$
}

${ }^{1}$ Associate Professor, Department of Surgery, Era's Lucknow Medical College and Hospital, Lucknow, U. P.

${ }^{2}$ Senior Resident, Department of Surgery, Era's Lucknow Medical College and Hospital, Lucknow, U. P.

${ }^{3}$ Assistant Professor, Department of Surgery, Era's Lucknow Medical College and Hospital, Lucknow, U. P.

\section{BACKGROUND}

Hydatid disease of the spleen should be kept as the differential diagnosis of all cystic masses in the spleen/abdomen. The anatomical relations of splenic hydatid cyst should be demonstrated before surgery because of varied presentations. Although the management must be individualised for each patient, a surgical resection is the best curative procedure. Postsurgical pharmacological treatment is necessary to ensure complete healing.

\section{KEYWORDS}

Primary Splenic Hydatid Cyst.

HOW TO CITE THIS ARTICLE: Tahir S, Ahmad S, Asif S. Primary splenic hydatid cyst - A case report. J. Evolution Med. Dent. Sci. 2016;5(94):6970-6971, DOI: $10.14260 /$ jemds/2016/1576

\section{BACKGROUND
Hydatid disease (echinococcosis) is a zoonotic infection} caused by the larval form of parasites of tapeworm, Echinococcus granulosus. Humans are the accidental intermediate host in the development cycle of hydatid disease. Although hydatid disease affects any organ or soft tissue, it is most frequently found in liver (60-70\%), lungs (30\%), and rarely encountered in the kidney, spleen, bone, thyroid, breast and pancreas. Splenic hydatid disease is very rare with its occurrence less than $3 \%$ of the total incidence of Echinococcosis even in endemic areas. Berlot first described splenic hydatid cyst as an autopsy finding in 1790.(1) Primary infestation of the spleen usually takes place by the arterial route after the parasite has passed the two filters (hepatic and pulmonary).

\section{Case Report}

A 50-year-old female patient, housewife by occupation, presented to our general surgery clinic with a mass in the left upper abdomen since 10 years. There was left hypochondriac dull aching pain which did not shift or radiate. Lump as stated by the patient was progressive in nature, with history of decreased appetite and fullness of stomach. She had no history of jaundice, cough or respiratory distress, abdominal trauma, weight loss and her past medical history was unremarkable. Physical examination showed an asymmetric abdomen and a growing lump with smooth surface in left hypochondrium with palpable splenomegaly. Abdominal CT scan shows large homogenous cystic lesion in spleen with many septae, originating from the spleen. The cyst in the spleen appeared to fill the left quadrant of the abdominal cavity, most likely suggestive of hydatid cyst. There were no cysts in other

Financial or Other, Competing Interest: None.

Submission 20-10-2016, Peer Review 11-11-2016,

Acceptance 19-11-2016, Published 24-11-2016.

Corresponding Author:

Dr. Saleem Tahir,

Associate Professor

Department of Surgery,

Era's Lucknow Medical College and Hospital,

Lucknow-226003, Uttar Pradesh, India.

E-mail:dr_tahir75@yahoo.com

DOI: $10.14260 / j e m d s / 2016 / 1576$

\section{(c) (1) $(9$}

abdominal viscera. A radical splenic resection was done via left subcostal incision with removal of the hydatid cyst and section was sent for histopathology examination which came out to be a hydatid cyst.

\section{Specimen-Splenic Hydatid}

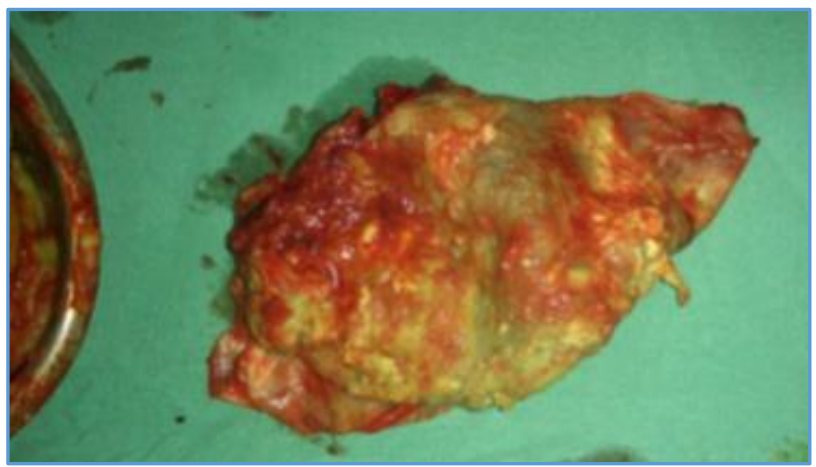

\section{CT Image}
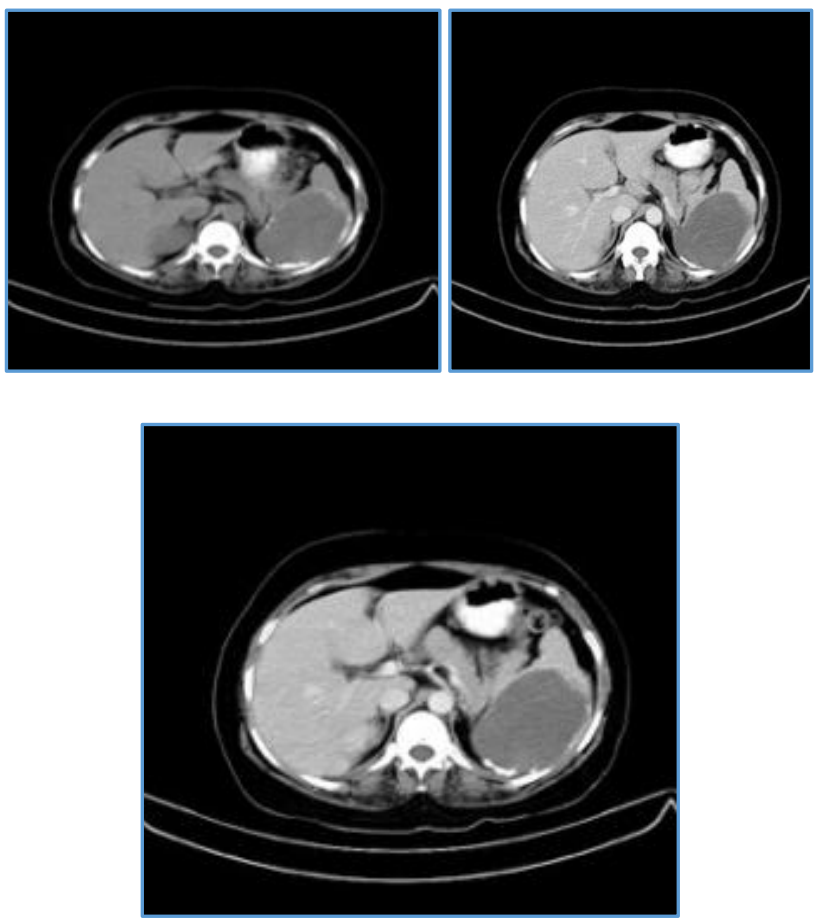


\section{Histology}
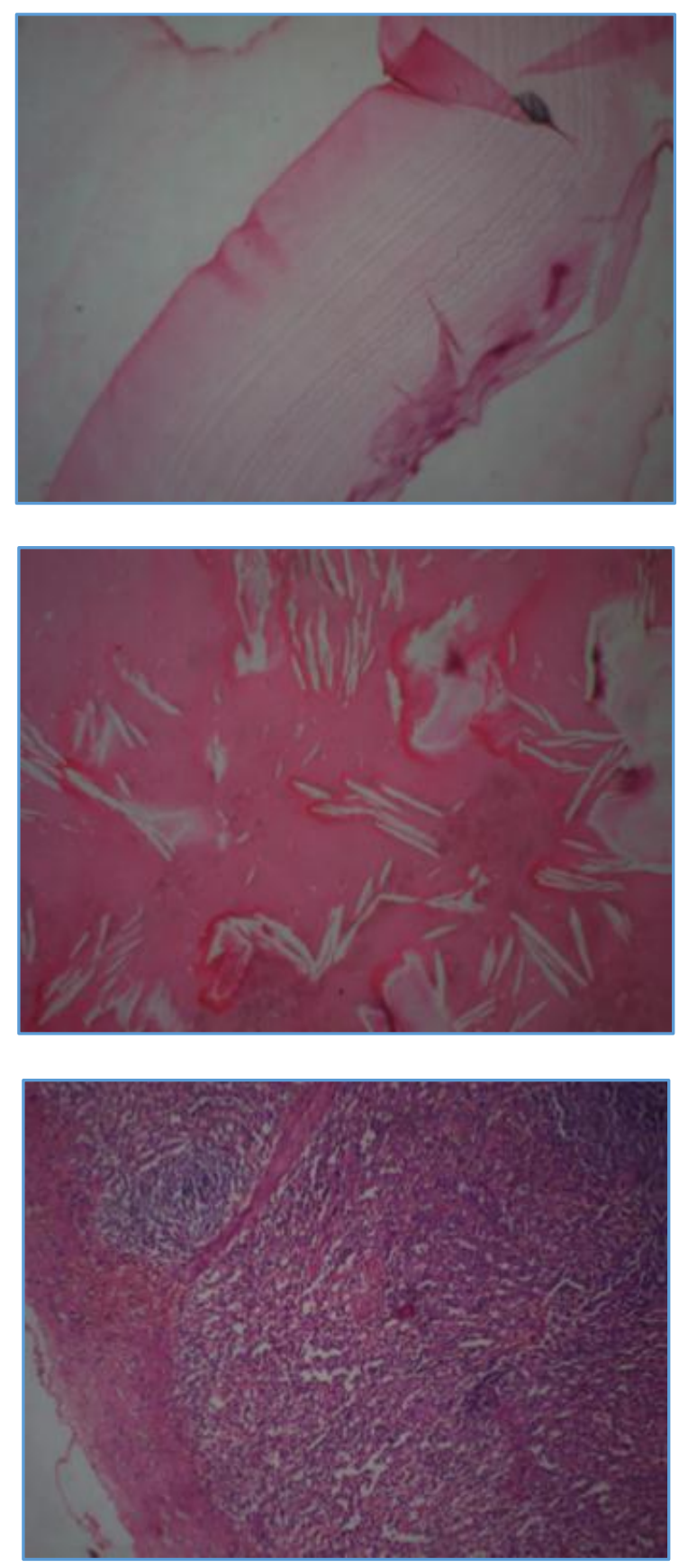

\section{DISCUSSION}

Splenic hydatid cysts are usually asymptomatic, solitary slow growing and incidentally diagnosed. The main symptoms associated with the disease are abdominal discomfort, pain and palpable mass in the left upper quadrant. The complications of untreated splenic hydatid cyst are mainly secondary infection, inflammation (Lippit et al., 1967), and acute abdomen, compression of other viscera, intra-abdominal rupture and fistulisation to the bowel, mainly colon causing severe pain and may prove to be life-threatening pericystic inflammation, may cause adhesions with nearby organs such as the kidney, left diaphragm, colon, stomach.(2) The main differential diagnosis of splenic hydatidosis are cystic lesions of spleen such as splenic abscesses, epidermoid cysts, haematomas, post-traumatic pseudocyst neoplasms like lymphangioma and haemangioma.

Pre-operative diagnosis may be difficult. Eosinophilia may be the finding on haematological investigation. Radiological diagnosis by plain x-ray, Ultrasonography (USG), CT and MRI can also be used to diagnose hydatidosis. The standard treatment is splenectomy (Berrada S et al, 1991) as complete resection removes all parasitic and pericystic tissues. ${ }^{3}$ During surgical treatment extreme caution must be taken to avoid rupture of the cyst. Albendazole is an effective adjuvant therapy in the treatment of hydatid cyst. There are less chances of recurrence in patients who receive albendazole therapy.

\section{CONCLUSION}

From the above study we could conclude that hydatid disease of the spleen should be kept as the differential diagnosis of all cystic masses in the spleen or the abdomen in general. The anatomical relations of splenic hydatid cyst should be demonstrated before surgery on account of varied presentations to decide the best treatment modality.

Although the management must be individualised for each patient, a surgical resection is the best curative procedure. Postsurgical pharmacological treatment is necessary to ensure complete healing.

\section{REFERENCES}

1. Tarcoveanu E, Plesa A, Danila N, et al. Splenic hydatic cyst. Observations upon 38 cases of splenic echinococcosis. Revista Medico-Chirurgicala a Societatii de Medici Si Naturalisti DinIasi 2002;107(2):311-5.

2. Lippitt WH, Akhavan T, Caplan GE. Epidermoid cyst of the spleen with rupture and inflammation. Archives of Surgery 1967;95(1):74-8.

3. Berrada S, Ridai M, Mokhtari M. Hydatid cysts of the spleen: splenectomy or conservative surgery. Ann Chir 1991;45(5):434-6. 